\title{
The New Agora: Social Media as a Vector for Sign Language as a Language of Culture, Identity and Inclusion of the Deaf
}

\author{
Cayley Guimarães \\ UTFPR \\ cayleyg@utfpr.edu.br
}

\author{
Sueli Fenandes \\ UFPR \\ suelif@,oglobo.com
}

\begin{abstract}
Sign Languages (SL) are necessary for the intellectual development of Deaf children. They are complete linguistic system used by the Deaf Culture for education, communication, creation and dissemination of knowledge. Arbitrarily forbidden for more than 100 years, the lack of SL artifacts is now a major problem the Deaf: there are few loci where they can interact in their own language (i.e. there are few media in SL). The recent growth in social media (virtual applications that allow the user to create and share their own content) has provided a new vector for the use of SL (whether in real time, or separated in space and time) and value SL as a Language of culture, identity and inclusion. The research surveyed Deaf students of a Bachelors program in Linguistics and shows that social media has become a new Agora for the Deaf Culture.
\end{abstract}

\section{Introduction}

Language is necessary for intellectual development of children [1]. Born to hearing parents, Deaf children are incapable to have easy access to the oral language. The Deaf have even less opportunities to learn SL (i.e. there is a lack of school for the Deaf); additionally, there is a lack of educational, cultural, social artifacts the Deaf children can use and a lack of linguistic centers in which the children can be immersed with others using SL and learn the language naturally [2][3][4][5]. SL is a complete linguistic system, deemed important for the human development of the Deaf; and it is the language used by the Deaf to partake in their community [2]. The lack of early exposure to SL combined with scarce opportunities to speak their own language is detrimental to citizenship and culture [5][6]. Additionally, identity occurs in the encounters with people of the same community and culture, in places and situations where new discursive environments are organized [3][4]: the lack of SL prevents the Deaf of form their identity.

Arbitrarily forbidden for over 100 years, only recently SL has entered the research agenda; and few of these studies approach the use of SL from the social, cultural aspect [7]. We find in [7][8][9] that, in one hand, most studies take the wrong approach in developing such tools: they are developed by hearing people, and use the oral language (inaccessible to the Deaf). Also, the Deaf have difficulties to acquire a writing system, be it of the oral language, or of the SL [9][10].

Various products that claim to attend to the Deaf, such as television shows, merely provide a written closed-captioned option (ignoring the fact that most Deaf people do not know this modality of the oral language) [9]. Some artifacts use technological sensors in gloves (which would be the same as putting sensors in a person's tongue and tell her to speak). Other artifacts are based on a one-to-one translation from the oral language to SL $[11][12][13][14]$.

For Lucas and Valli [15], the lack of language contact is one of the major sociolinguistics issues in the Deaf community. The authors claim that there are more distinctions than the dichotomy proposed by the deaf/hearing contact. For example, the authors say that both the Deaf and the non-Deaf can be bilingual; or, in another instance, the Deaf may be an individual who was mainstreamed at an early age and learned to sign relatively late; or they can be hearing children of Deaf parents, or hearing individuals who learned SL $[16][17][18][19]$. So, it is important to take those differences into consideration when designing artifacts that are valuable to empower the Deaf to live their unique human experience.

On the other hand, the use of social media has increased to the point that it now encompasses all aspects of human activities. The emergence of social media has changed the way people share information and express opinions with others: by posting and sharing information, commenting on posts, sending links and messages and small videos, for example. 
Communication mediated by social media can be synchronous (where users are simultaneously connected) or asynchronous (where a user may send out a message for others to see at a later time). But they serve many purposes (e.g. keep in touch). Kaplan \& Haenlein [19, p. 60] define social media as "[...] Internet based applications that allow the creation and exchange of content which is user generated". According to the authors, some people have grown up using such technologies; older people have to adjust; either way, the Internet is part of our daily lives. And part of Deaf people's lives.

There are several studies about the use of social media and its impact: Social media increase perceived social identity (i.e. the identity construed within a group due to similar characteristics, interests and/or opinions). Some studies found that reading comments on social media contributes to social support and that social media permeates our lives, and allow students to share ideas, build communities to collaborate, facilitate learning, reach out to learn and teach. Several studies have shown the effects of social media use on student's academic performance, ability to engage and the effect on their lives [20] [21][22][23]. Users and communities can create, collaborate and edit user content, in a dynamic environment that allows for participation, retrieval and sharing. The increase in use of social networks does not decrease the academic performance of the students. The use of social media has disadvantages: cyber bulling, virus, distractions [25][26][27].

Unfortunately, to the best of our knowledge, all of these studies consider the use of social media by nonDeaf people, using the oral language (either spoken or written) in a manner that is not conducive to value $\mathrm{SL}$ as a language of culture. However, there is evidence of various uses of social media by the Deaf using videos - they post video blogs, SL lessons, stories etc.

This research investigated the use of social media by Deaf students of a Bachelors program in Linguistics/SL and how they have helped the Deaf to learn more about SL, connect to friends and families, create technological social media groups to scaffold learning and to serve as a meeting place where they can express their thoughts and feelings in their natural language. The main findings were that the Deaf use social media as a platform from which they can create a social network of Culture.

The remainder of this article briefly discusses the computer-mediated communication; the Deaf Culture and the importance of Sign Language. It also brings some theories of digital anthropology. Next, it presents the results un(related) studies in social media. The research methodology consisted of a survey in SL, followed up by short, semi-structured interview where the participants shared their experience using the Critical Incident Technique (i.e. the subjects where asked to elaborate on an episode where the use of social media helped them with the use of SL). The results indicate a need to incorporate new features into existing social media (or even create new ones, that allow the Deaf to use SL).

\section{Digital mediated communication Culture}

Language and communication with people are paramount to create understanding and appreciation for diverse cultures and perspectives. Traditional social venues such as school, clubs, associations and church, for example, provide opportunities for important human interaction and socialization [21]. In the digital environment, individuals are capable of finding those who share the same linguistic codes, like SL, and thus are exposed to learning, exchange of experiences, diversity of information [22] whereas otherwise they might be isolated (e.g. consider the case of a Deaf individual living in rural areas). The Deaf may also find others who use the written form of the oral language, and try to expand their inclusion into that world, and increase their social life.

Most social media studies show that the value of using social media is that it builds relationships through making new friends that participate in social communities [23][24]. Social media use also allows for members to support one another [25]. As such, the use of social media is related to social capital gains [24]. Putnam [26, p.67) describes Social Capital as the "features of social organizations such as networks, norms, and social trust that facilitate coordination and cooperation for mutual benefit". Social capital can be expressed when the ties refer to emotionally supportive relations. In other words, social capital is what is acquired through relations among people who trust one another, who are more inclined to share personal experiences and help their peers, count on the collaboration of others, reduce conflicts. Social media interaction can increase selfesteem [27] through conflict resolution; and can reduce uncertainty and suspicion of others. For example, [28] shows that the use of social media makes individuals feel happier.

Many research has shown that social media is more interactive (than traditional media such as television): they allow for interactions with various people who regardless of political, socio-economic and geographical barriers [24][25][26][27][28][29]. 
Unfortunately, most social media available are designed for non-Deaf people (i.e. heavily relied on text). But social media that provide the ability for the user to post video and to make video calls present a new opportunity for the Deaf. Given that social interaction and communication provide social support and sense of belonging, it is valid to research how the Deaf are using these new social media for their well being [29].

\section{Sign Language and Deaf Culture}

The lack of SL acquisition by Deaf children prevents them to have full access to intellectual development: the human being needs language to learn. Humans learn by asking, comparing, clarifying doubts, and mostly by forming abstract, complex thoughts via language. This is the general process by which one learns to develop cognitive structures: one compares, combine new and old knowledge, makes inferences, use mental processes that are mediated by language. [1][2][3][4]

SL is the natural language of the Deaf without which Deaf children are subject to dire consequences. There is a great incidence of inadequacies among the Deaf throughout their lives: they have difficulties to form relationships; they do not develop abilities to control impulsive behavior; they are dependent on the visual and concrete aspects of the situation and they lack socialization skills [13][15][17][18].

Language is fundamental not only for intellectual development but to social functions, culture, education and citizenship, among other human activities. Deaf people should be able to take part in the world surrounding them. Unfortunately, there are educational, social and technological barriers that deter access to Deaf Culture. The Deaf are relegated to a reality where there is little opportunity to develop language skills and abstract concepts in their own natural language and culture. [1][2][3].

These barriers put the Deaf in a position of failure regarding higher achievements when compared to other social groups [1][2]. This is apparent when one observes that non-Deaf children learn to hear in their own family, and therefore is able to integrate into the oral language in a social and interactional process [29]. The Deaf should be allowed and supported in their quest to create their own knowledge in SL. Such use of SL will allow for linguistic, social and cultural development, because things start to make sense when the Deaf is a participant in the collective construction of meaning.

Social media, with its possibilities of creating and disseminating user created content in video, using $\mathrm{SL}$, is the focus of this research.

\section{Digital Anthropology}

Can human interaction over the Internet be the new Ágora for Deaf people? One has to ponder, especially since new technology is often seen as a threat - the phone would stop visitation among friends and the Internet is no stranger to this suspicions [26]. Much has been discussed about the pros and cons of social media as mediator of interaction, but the studies are mostly focused on an individual behavior towards her needs. There are few studies that consider the larger implications that such technology may have for inclusion of Deaf communities. Some studies have concluded that online interactions often lead to offline engagement with civic activities. Online interaction can supplement rather than supplant face-to-face interaction, and help to maintain geographically dispersed networks [30][31].

This research aligns with Daniel Miller [32] and takes into consideration the importance of the contemporary anthropology of reflecting on a world that is increasingly digital in manner. Society can be better understood from the point of view of its digital materials, meanings and practices of the groups and the social media [32].

Miller [32] claims that the studies in social media are not relevant when it comes to empower the Deaf and the use of SL. The online world is seen as virtual, and a social media friend is not considered a real friend. But all forms of communities should be seen as equal: to do online activities is part of our daily lives. A telephone conversation is no less real due to its use being mediated by technological processes. Therefore, new studies should be conducted considering the use of social media as a vector to value SL as a language of culture.

Miller [32] considers new perspectives to theorize these new social environments: the way in which the digital encompasses both the particular and the universal part of modern life; the way in which most studies define the digital by its binary code and how we should refute such conception keeping to a more holistic approach; the material nature of the digital (i.e. it allows for the study of social media as integrated into daily lives of Deaf people).

The author tells us that digital communications frequently have some anthropological basis (e.g. in India, the cast system is central in the way social media is used; in Turkey this use is more tribal). The studies should link the individual to the social, and the use of social media is different in different cultures [32].

As for the cultural meaning of behavior, traditions suggest that cultural life is normative (i.e. people are 
concerned with the manner in which they will be perceived and judged) and the social media are part of this norm, exposing more of the individual.

Miller [32] introduces the concept of Polymedia: the analysis of modern social media is interconnected, and the meaning of any media tends to be defined by the contrasts and complementarities with other media. For example, Twitter can be seen as informational (and since it is basically designed to work with written text, it may not be a media of choice for the Deaf); Instagram can be linked to visual questions. Snapchat is transitory, as opposed to the long-term use of Facebook.

Technological and economical access to social media is increasingly cheaper, universal, and the artifacts are becoming easier to use. The choice of which media the Deaf will use is a personal choice, and should consider the manners in which the social media will facilitate the use of SL as part of the desired social interaction. This choice in itself is a social construct, given that it is social and moral.

Social media can be seen as the basis of the process to create wider social interactions, and allow for a variety of linguistic-discursive dynamics of the use of language. To the extent of our knowledge, it is fair to say that the Deaf have not been considered as a social being in this context (i.e. with the right to be seen as a capable human being), and this historic posture has denied the Deaf means to construct her identity, belonging to a community, able to selfidentify by the relations provided by SL.

If such social contacts do not occur, how is the Deaf going to create identities? Where can they find meaning to their understanding of the world and themselves? The rise of social media has brought a new light into these questions, and a new vision concerning the Deaf and their communication concerns are now a possibility. Although the Deaf cannot hear, they are capable of using social media to conquer independence, provided that they can reinvent their own nature, and share, within the peculiarities of their SL, interactive situations. Social media can be seen as a vector where those opportunities are present for creation, communication, political participation, full citizenship exercise: the new Ágora, a space that is conducive of social encounters; a place that brings communities together, regardless of space and time in a new form of social organization; a place to learn and teach.

\section{Un (related) Social Media Studies}

The emergence of social media has changed the way people share information and express opinions with others. Kaplan \& Haenlein [16, p. 60] define social media as digital applications " [...] that allow the creation and exchange of content which is user generated". Some people have grown up using such technologies; older people have to adjust; either way, the Internet is part of our daily lives.

Social media increases perceived social identity (i.e. the identity construed within a group due to similar characteristics, interests and/or opinion). For example, Rozzell et al. [33] found that reading comments on social media contributes to maintain contact and increase social support.

Even though the possibilities and the several positive support of inclusion, access, and social development that the use of social media should bring to the Deaf community are clear, there are few studies on how better these media should value SL.

A review of the design and implementation of web-based, open source technology for personcentered learning (i.e. meaningful learning that combines cognitive skills and the experience, the idea and the meaning) and teaching (i.e. climate of trust to nourish natural desire to learn so that students become life-long learners) was conducted at a university and discovered that students used social media for cooperation, exchange and discussions with colleagues and teachers) [34].

The use of social media has shown that the group is perceived as a whole; that it imbues direct concern with the group process; that it allows for users to achieve shared goals; that it provides feelings of connectedness an community. It has also showed that participants are more at easy about communicating their own feelings; that they tend to tolerate sharp differences, ambiguities and conflicts in an attentive climate of respect, caring and trust [32][33][34].

Bonds-Raacke \& Raacke [35] found that people spend more time in social media than ever, to gather and share information, to keep in touch with families and friends and to find and make new friends. But the authors have found that users are facing an increase of information overload, and that there is a lack of connectedness among the different social media, making it difficult to keep up with new information.

Mocanu et al. [36] found that attention patterns of users are similar, even though the information they are receiving are very different in nature - that is, "fake news" and "conspiracy" theories reverberate for the same amount of time as other information. Junco et al. [37] showed that twitter can engage students who use it in order to play an active role. Tamir \& Mitchell [38] found that disclosing information that is personal activates the area of the 
brain that is related to pleasure. Luna et al. [39] created an ontology to analyze the characteristics and preferences of the user and the context in order to find the relationships generated when a person interacts in a defined context.

Chun \& Lee [40] found that willingness to share personal information on social media increases when there is an enhance perception of control found in the congruency of their opinion and that of others.

Grapendorf, Sassenberg and Landkamer [41] found that mindfulness (known to improve face to face negotiations and decision making) is detrimental to the performance in computer-mediated business tasks

\subsection{Social Media and the Deaf}

Bishop, Taylor and Froy [42] discuss the potential of computer-mediated communication to reduce the social isolation experienced by the Deaf, and found that the subjects demonstrated that the use of social media could be less stressful.

Barak and Sadovsky [43] showed that the use of social media brought extra benefits for the Deaf because it is a means of communication that is primarily based on visual and images, and not on the auditory channels; and that the Deaf were more prone to use social media, and concluded that the use of social media may be seen as an empowering aid. Other studies treated the Deaf as deficient, such as [44] that conducted a study on the implications of communication as social engagement for interactions between Deaf and non-Deaf people. Donovan [45] examined the online health information seeking practices of the Deaf using existing tools based on the oral language, which mirrors the findings of Zazove et al. [46] that the use of Internet was associated with the English language. Lomick and Blogg [47] found that Deaf people relied more on blogs and vlogs as important communication tools during a social movement activisms at a school for Deaf.

As can be seen, most of these studies treat deafness as a disease to be hidden from others. We find in Möbus [48] one of the few studies that are concerned about the use of SL to make digital content accessible. Valentine and Skelton [49] explore how the Deaf are using the Internet to communicate within their community given a new space and boost to their activities. And Blom et al. [50] explores ways in which Deaf people find online friends. This is a clear call for further research on the informational and communication practices of the Deaf using SL in social media.

\section{Research Methodology}

The research was exploratory in nature, developed to gain an insight on the informational and communicational practices of the Deaf using SL in social media. This kind of research is better suited when the object of research is little explored, and it is thus difficult to formulate precise hypotheses and concrete testable variables. According to Ariboni e Perito [51] exploratory research aims at developing and clarifying concepts for further investigations. The results of a qualitative research may provide useful information on the subject.

The research consisted of a questionnaire in SL asking about the use of social media in SL. There were 50 respondent subjects, all Deaf students of a Bachelor's course in Linguistic/Sign Language. They were all briefed about the research, and gave consent to their volunteered participation. After the questionnaire, the research used the Critical Incident Technique [52] to ask 10 subjects to relay a situation where the use of social media in SL was important for their participation in the Deaf community. The answer to this question brought up several considerations about education, family and learning and teaching of SL.

\section{Results}

Most respondents came from non-Deaf families, and had no access to SL: they were forced to learn the oral language, within the family and at hospitals, medical clinics and school, with little success and a lot of frustration, and an overall intellectual underdevelopment. They relied on images from television, and visual observations to draw conclusions, mostly wrong, about their surroundings.

Most respondents said that their first contact with other Deaf, and with SL, was at church. Brazilian churches have a very developed program to preach and hold mass in SL. Most of the signs the participants learn are specific to the religion, created by hearing people - that raises the question of the validity of the language.

$85 \%$ of the Deaf said that they had a good proficiency in SL, and only $32 \%$ reported they had some proficiency in the oral language. Given that this were students of a linguistics course in SL, one is left to wonder about the proficiency of other Deaf who had no access to school. All Deaf said their families had no proficiency in SL.

When asked about which social media they used in SL, most respondents agreed that the media that allowed for the use of video (and therefore of SL) 
where the most important: for example, the Deaf use Facebook to post videos and comment on friends post, Snapchat to share videos and Whatsapp to make phone calls via the use of videos. Different than other groups, the 45 of the respondents do not use social media that is mostly based on the written form of the oral language.

One respondent says: "[...] Only when I was 3 that my mother discovered that I was Deaf; and dictated that I learned the oral language. She used to beat me and forbid me to use gestures". Another respondent said that [...] she learned to copy the words, without really understanding what they meant". And yet another said that only when she was already 14 years old "[...] that she met other Deaf people in church, and started to learn SL". The most poignant response was of a student who remembered asking her teacher why Deaf people died so young, because "[...] she had no contact with Deaf adult".

And other stories reported went along those lines: families and school, and all the doctors and health professionals forcing the Deaf to acquire the spoken (or even the written modality) of the dominant oral language. This oppression may be linked to a lot of prejudice, isolation and development delays [1][2][3].

Social media is part of the respondent's daily lives, where they spent as much as 4 to 5 hours a week, which shows that social media is an integral part of their activities.

All respondents said that they use social media mainly because of the video capabilities to send a video message, to arrange encounters, to learn different regional variations of signs, among others.

And they were able to cite several applications that allowed them to use SL, such as:

- Youtube - The Deaf use this tool to post videos in SL. To see videos posted by other Deaf. To learn SL. To learn some school subject. The respondents see this as the most important tool for learning and education, and to keep up with posts of what other Deaf are doing. And to post videos of their daily activities. They reported that they followed several channels with Deaf related materials, in SL.

- Facebook - this tool played a major part in a social movement that gathered the Deaf to protest the government project to close the National School for the Deaf - four thousand people were gathered in Brasilia, the countries capital, thanks to information dissemination and coordination that occurred via this tool.

- Facebook - After the movement against the closing of the National School for the Deaf, the Deaf movement's leadership wrote an open letter to the Minister of Education against economic measures that would affect other schools for the Deaf as well. The letter was written in Portuguese, and a video version of it was posted on Facebook.

- IMO [53] - an application, similar to whatsapp, that allowes for video calls.

- OOVOO [54] - another application, similar to whatsapp, that also allows for video calls.

- HANDTALK [55] - an application used to translate conversation from the oral language to SL. This application allows both the Deaf and non-Deaf to learn SL.

- PRODEAF [56] - another translator to allow communication between the Deaf and the nonDeaf. This application allows the Deaf and nonDeaf to learn SL.

- $\quad$ Skype - a tool where they can make video calls. As can be seen, all the related work have not even mentioned such applications, let alone considered the study of the use of such applications by the Deaf.

The next group of questions allowed for multiple answers, so graphs show the frequency of responses to each question and category See figure 1 for the reason they joined the course:

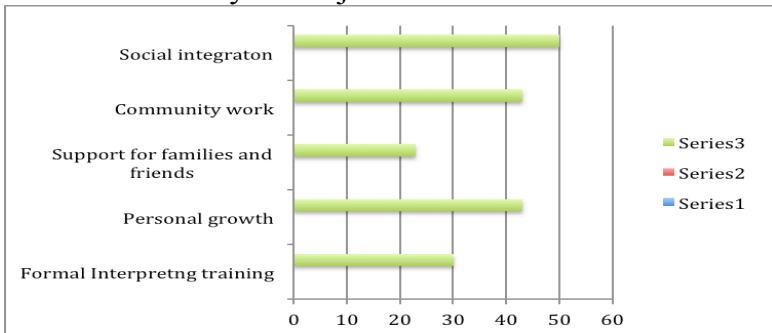

Figure 1. Reasons to join the linguistic course in SL.

Figure 2 shows the isolation in which the respondents find themselves, when most report that they use social media for mainly social functions communication, leisure and integration.

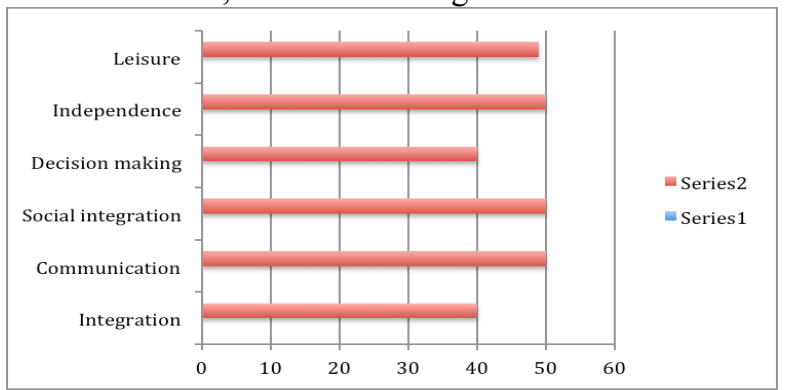

Figure 2. The importance of use of Social Media.

The use of social media is important for the Deaf's need to seek information in daily life: all respondents said that the lack of interpreter, dictionaries in SL an lack of education material lead 
them to seek information with their peers in social media. Figure 3 shows their greatest needs for information seeking, and most of them can be related to the lack of SL access and opportunities for citizenship exercise:

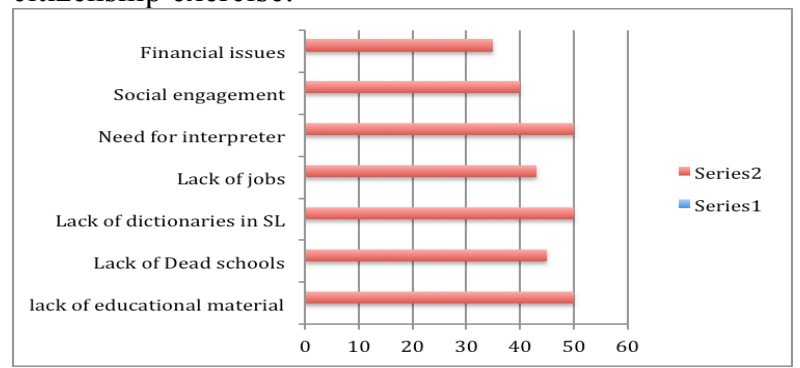

Figure 3. Reasons to join the linguistic course in SL.

The main motivation of the Deaf subjects is to use social media to meet new friends, the lack of Deaf people near them and to learn, closely followed by identification with other Deaf people. The respondents also indicate a strong need to keep in touch with friends, form new relationships and to share information. These results can be seen on figure 4:

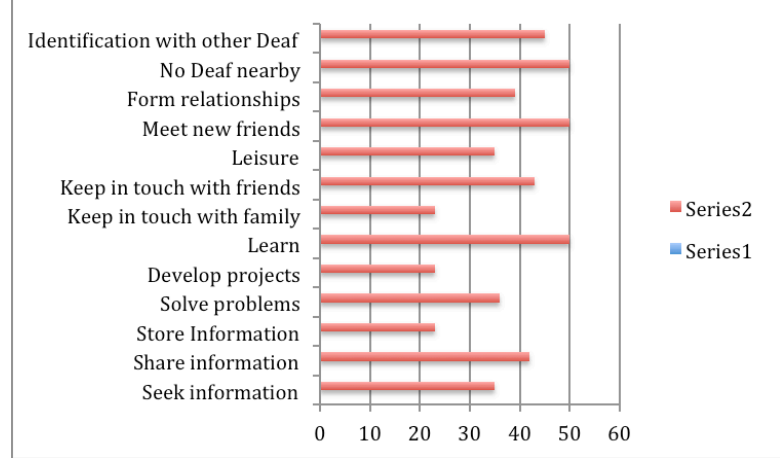

Figure 4. Main motivation to use social media.

When it comes to their use of the information they get from social media, all respondents said that they used it to create meaning to SL, learn SL and for social integration. The use of social media is considered to be important to understand the facts happening in society around them. The responses can be seen in Figure 5:

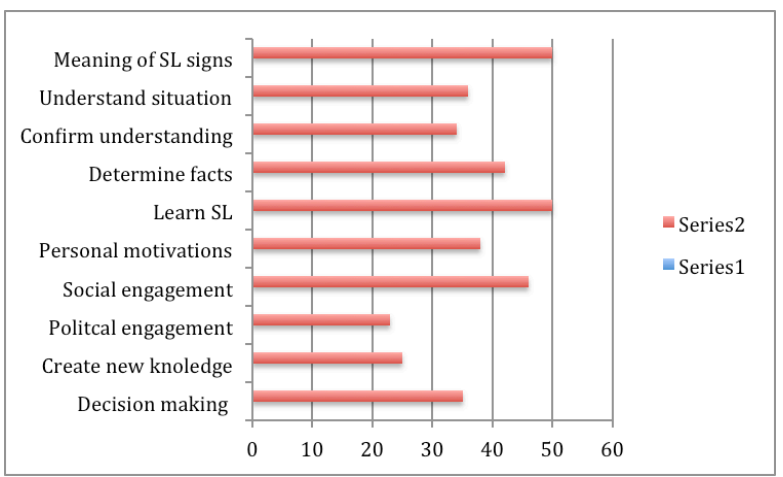

Figure 5. Main use of social media.

The respondents where given an adaption of the community questionnaire by Barret-Lennard (2005). Figure 6 shows that the respondents are able to share their personal struggles, common purposes, communicate their feelings, experience connectedness, and an overall feeling of belonging to a community where they can be among their peers: other Deaf using SL:

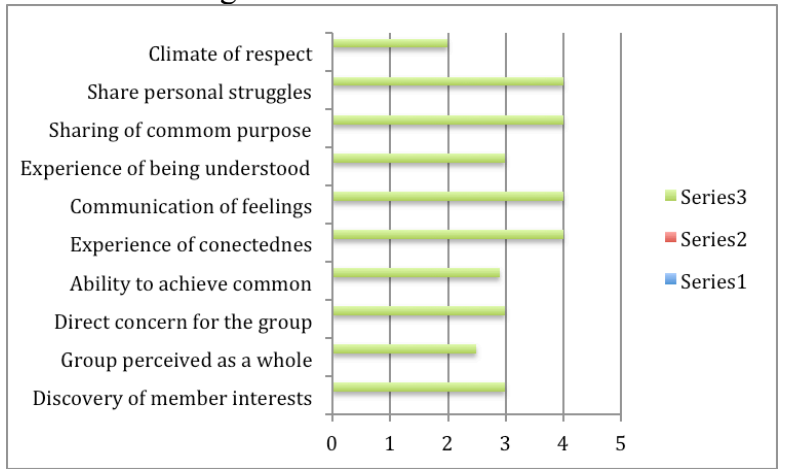

Figure 6. Feeling of community. Adpted from BarretLennard community questionnaire (2005)

\subsection{Results of critical incident interviews}

After the questionnaire, 10 students volunteered to narrate an episode where the use of social media was important for their life. The technique used was the Critical Incident Technique [52], and the question asked was: "Please, if you will, narrate an episode in your life where the use of social media in Libras was important". The interviews were conducted in SL. Below, we present a translated transcript of part of the responses:

- Respondent A: Youtube was very important to me. I lived in a small town, and my school had only one SL interpreter and only one other Deaf besides me. I could not learn the language and the subjects. I watched youtube videos all the time, and learned, and learned. 
- Respondent B: I found out on Facebook that the government was going to close down the National School for the Deaf. And that there would be no more money for interpreters in my school. By watching the posts, I became aware of the movement that was going to Brasilia to protest, and I went too. There were four thousand Deaf people.

- Respondent C: I came to this city from São Paulo, and most of the signs were different. The Deaf do not have contact with the Deaf of other cities. I used IMO to ask my friends to teach me the regional variations. I have also taught some friends new signs in SL that they did not know.

- Respondent D: I use IMO and OOVOO all the time to see if my friends are going out, where they are going, so that I can go too.

- Respondent E: We have a group on Whatsapp from church. We always exchange video messages about the Bible.

- $\quad$ Respondent F: I am learning SignWriting (i.e. the written modality of SL). We have a group on Whatsapp. We write the sentence on a paper, take a picture and post it, so that other members can comment and correct the writing. I have learned a lot. Some of the comments are in written Portuguese.

- Respondent G: My boyfriend is non-Deaf. We use a lot of HandTalk to communicate. He writes the sentence in Portuguese, and the application translates it to SL for me.

- Respondent H: I used HandTalk in a medical consultation. I was alone, and I couldn't explain what I was feeling. There was no translator.

- Respondent I: Our groups from the university talk all the time to study.

- Respondent J: I spend a lot of time on the Internet, because that's where I find most of my friends. We talk about several things like going out to the movies, shopping, going to the park.

\section{Considerations}

Considering the exploratory nature of this research, more than answers, the authors which to bring the precarious status quo of the Deaf when it comes to participation on the modern society. They rely on the use of social media for important human activities, such as learning their own language, find out about the latest news; create meaning of the facts surrounding them. The reflection to be made here is that the difficulties the Deaf face to inclusion and full exercise of citizenship may be compromised due to adequate access to vital societal information.

Those difficulties could be avoided by the implementation of education policies that incorporate SL into the educational curriculum, and by the creation of new technologies that would allow for more reliable information access. As presented on the related work, the non-Deaf behavior is somewhat different than the use of social media from the Deaf.

Therefore, the Deaf make the most of the video capabilities of the social media to their advantage which is good, but show that there is a need and a clear call for the Computer Science to consider the needs of the Deaf to inform the design of more artifacts that are adequate and geared towards the needs of the Deaf, so that the use of new social media artifacts, specially designed for their abilities (instead of requiring the Deaf to adapt to existing technology that is only marginally useful to them) are a valid contribution to their social inclusion.

The research also brought to light some other social media that are widely used by the Deaf people, but, to the extent of our knowledge, have not been studied.

The authors understand that some of the consequences of not having early access to language (i.e. SL) prevent intellectual development, prejudices, abuses, lack of information, lack of learning and job opportunities and others are reflected in the use of social media by the Deaf for basic human rights to assemble, make friends, learn their natural language, make friends. These problems are not to be solved by social media alone, but they require a genuine will to consider the value of the Deaf as a person who experiences human life in a different way [1][2]. These issues go beyond the mere access to social media. And certainly they would be best attended by a real understanding of the Deaf issues, and consequent political actions.

Their age, background history within the Deaf community, their expertise in technologies and gender were not considered. Another question that remains open: do the Deaf use the now widely known emojis to express their ideas when the media only allows for written commentaries? There is a clear call for studies that could focus on these new social media that the Deaf are using to answer more important questions that this study put in evidence.

\section{References}

[1] Vygotsky, L.S., Mind in society: the development of higher psychological processes, Harvard University Press, Boston, MA, 1974. 
[2] Fernandes, S., Educação dos Surdos, IBPEX, Curitiba, 2012.

[3] Skliar, C., Atualidade de educação bilíngue para Surdos, Mediação, Porto Alegre, 1999.

[4] Sánchez, C. La educación de los sordos en um modelo bilíngue, Diakona, Mérida, 1991.

[5] Hoffmeister, R., Famílias, crianças surdas, o mundo dos surdos e os profissionais de audiologia, In: C. Skliar (Org.) Atualidade da educação bilíngue para surdos. Mediação, Porto Alegre, 1999.

[6] R. Jonhson, S. Liddell, C. Erting, "Unlocking the curriculum: Principles for achieving access in deaf education". Gallaudet University Research Institute, DC, 1989.

[7] Guimarães, C. et al., "Pedagogical Architecture Internet Artifacts for Bilingualism of the Deaf (Sign Language/Portuguese), 46th HICSS, Hawaí'I, p. 40-49, 2013.

[8] Lodi, A.C.B., Letramento e minorias, Ed. Mediação, PA, 2002.

[9] MacNamara, J., Names for things: a study of human learning. The MIT Press, Cambridge, MA, 1982.

[10] J. Kyle, "Beginning Bilingualism", Ibero-American congress on bilingual education, Lisbon, 2005.

[11] J. Cummins, "Linguistic interdependence and the educational development of bilingual children", Review of Educational Research, 49(2), p. 222-251, 1979.

[12] Nover, S., Andrews, J., Critical pedagogy in deaf education: Bilingual methodology and staff development. New Mexico School for the Deaf, NM, 1998.

[13] Allen, T., Patterns of academic achievement among hearing impaired students: 1974-1983, In: A. Schildroth, M. Karchmer (Eds.), Deaf children in America, p. 161205., College-Hill Press, CA, 1986.

[14] Pettito, L., On the equipotentiality of signed and spoken language in early language ontogeny, In: D.D. Snider, Post Milan ASL and English literacy: issues, trends and research, p. 195-215, Gallaudet University College of Continuing Education, 1994.

[15] D. Lucas; C. Valli. "Languages contact phenomena in the American Deaf community. San Diego: Academic Press. 1989.

[16] A. M. Kaplan; M. Haelein. "Users of the world, unite! The challenges and opportunities of Social Media". Business Horizons, 53. P. 59-68. 2010.

[17] L.C. Cagliari, "Algumas questões de Linguística na Alfabetização”, Univesp, São Paulo, p.72-83, 2012.

[18] R. Rojo, "Alfabetização e letramento: sedimentação de práticas e (des)articulação de objetos de ensino", Perspectiva, Florianópolis, v.24, n.2, p. 569-596, 2006.

[19] C. Ewoldt, "A descriptive study of the developing literacy of young hearing impaired children", Volta Review, 87(5), p. 109-126, 1985.

[20] E. Alwagait, B. Shahzad, S. Alim. "Impact of social media usage on students academic performance in Saudi Arabia. Computer is Human Behavior. P. 1092-1097. 2015 [21] S. Benhabib. "Studying the self?". Roultledge: New York: Psychology Press. 1992.

[22] J. Brundidge. "Encountering difference in the contemporary public sphere". Journal of Communications, 60(4). P. 680-700. 2010.
[23] B. Kim; Y. Kim. "College student's social media use and communication network heterogeneity". Computers in Human Behavior. 73. P. 620-628. 2017.

[24] C. H. Jim. "The role of Facebook user's self-systems in generating social relationships and social capital effects". New Media \& Society. 17(4). P. 501-519. 2015.

[25] Nabi, R. L., Prestin, A., \& So, J. Facebook friends with (health) benefits?: Exploring social network site use and perceptions of social support, stress, and well-being". Cyberpsychology, Behavior, and Social Networking, 16(10), 721e727. 2013

[26] R.D. Putnam. "Bowling alone: america's declining social capital". Journal of Democracy 61(1). P. 65-78. 1995.

[27] S. Cobb. "Social support as moderator of life stress". Psychosomatic Medicine. 38(5). P. 300-314. 1976.

[28] P. Valkenburg; J. Peter \& A. P. Schouten. "Friend network sites and their relationships to adolescent's wellbeing and social self-steem. Cyberpsychology Behavior, and Social Networking, 9(5). 2006.

[29] N. Kumar. "Facebook for self-empowerment?". New Media \& Society, 16(7). P. 1122-1137. 2014.

[30] N. Fairclough, Language and Power. Longman, Inc., NY, 1989.

[31] T. A. Wills. "Social support and interpersonal relationships". In M. S. Clask (Ed.), Prosocial behavior (p. 327). Thousand Oaks, CA: Sage Publications. 1991.

[32] D. Miller. "Social media in an English village. London: UCL Press. 2016.

[33] Rozzell, B., Piercy, C. W., Carr, C. T., King, S., Lane, B. L., Tornes, M. Wright, K. B. "Notification pending: Online social support from close and non-close relational ties via Facebook". Computers in Human Behavior, 38, 272-280. 2014.

[34] Motschnig-Pitrik, Renate; Standl, Bernhard. "Personcentered technology enhanced learning: Dimensions of added value. Computers in Human Behavior 29. 4010409. 2013.

[35] Bonds-Raacke, J.; Raacke, J. "MySpace and Facebook: identifying dimensions of uses and gratifications for friend networking sites". Individual differences Research, 8(1), 27-33. 2010.

[36] Mocanu, D.; Rossi, L.; Zhang, Q.; Karsai, M., Quattrociocchi, W. "Collective attention in the age of (mis)information". Computer in Human Behavior, 51, 1198-1204. 2015.

[37] Junco, R.; Heiberger, G.; Loken, E. "The effect of Twitter on college student engagement and grades". Journal of computer assisted learning. 27, 119-132. 2011.

[38] Tamir, D. L.; Mitchell, J. P. "Disclosing information about the self is intrinsically rewarding". Proceedings of the National Academy of Sciences, 109, 8038-8-43. 2012.

[39] Luna, V.; Quintero, R.; Torres, M.; Moreno-Ibarra, M.; Guzmán, G. "An ontology-based approach for representing the interaction process between user profile and its context for collaborative learning environments". computer in Human Behavior, 51, 1387-1394. 2015.

[40] Chun, J. W.; Lee, M. J. "When does individual's willingness to speak out increase on social media?

Perceived social support and perceived power/control". Computers in Human Behavior, 74, 120-129, 2017. 
[41] J. Grapendorf; K. Sassenberg; F. Landkammer. "Mindfulness is detrimental to performance in computermediated interdependent tasks". Available at http://dx.doi.org/10.1016/j.chb.2017.04.023 Accessed at 04/04/2017. 2017 Published by Elsevier Ltd.

[42] J.M. Bishop, L. Taylor, F. Froy.

"Computer - mediated communication use by the deaf and Hard-of-hearing", Kybernetes, Vol. 29 Issue: 9/10, pp.1078-1086. 2000.

[43] Barak A, Sadovsky Y. Internet use and personal empowerment of hearing impaired adolescents.Comput Human Behav. 2008; 24: 1802-1815. 2008.

[44] C. G. Najarian. "Deaf women: educational experiences and self-identity". Disability \& Society. V. 23 (2). 2008.

[45] P. Donovan. "Culturally Deaf people seeking health information get little help from the Internet". Available at http://www.buffalo.edu/news/releases/2011/09/12865.html Accessed in 04/04/17. 2011.

[46] P. Zazove; H. E. Meador; H. A. Derry; D. W. Gorenglo; S. W. Burdick; E. W. Saunders. "Deaf Persons and Computer Use". From American Annals of the Deaf. 148(5). P. 376-384. 2004.

[47] C. S. Lomick \& N. M. Hogg. "An examination of social movement activities at Gallaudet, a university for the Deaf". P. 674-695. 2010.
[48] L. Mobus. Making web content accessible for the Deaf via sign language". Library Hi Tech, 28(4). P. 569576. 2010.

[49] G. Valentine; T. Skelton. "Changing spaces. The role of the Internet in shaping Deaf geographies". Computer mediated Communication and Protest. P. 469-485. 2011.

[50] H. Blom; M. Marschark; M.P.J. Vervloed, H. Knoors. "Finding friends online: online activities by Deaf students and their well-being. PLoS ONE. 9(2). Available at https://doi.org/10.1371/journal.pone.0088351. 2014.

[51] S. Ariboni; R. Perito. "Practical guide for exploratory research". São Paulo: Unimarco. 2004.

[52] C Guimarães; T. Arce; R. Mattos. "Critical Incident Technique: a methodology to study information used by informatics companies". AJBM. 70(10). P. 780-788. 2013. [53] IMO Available at: https:/itunes.apple.com/br/app/imo-chamada-dev\%C3\%ADdeo-chat/id336435697?mt=8 Accessed at 03/04/17. 2017.

[54] OOVOO Available at: https://web.oovoo.com/ Accessed at 03/04/17. 2017.

[55] HandTalk Available at: https://handtalk.me/ Accessed at: $03 / 04 / 17 / 2017$.

[56] PRODEAF Available at: http://prodeaf.net/ Accessed at: $03 / 04 / 17.2017$ 